\title{
Relationship between students' performance on weekly task assessments and final practical exam at the preclinical restorative dentistry course
}

\author{
Muhammet Kerim Ayar $\odot$ \\ Department of Restorative Dentistry, Biruni University, Faculty of Dentistry, Istanbul, Turkey
}

DOI: $10.18621 /$ eurj.400696

\begin{abstract}
Objectives: The purpose of this study was to examine the relationships between dental students' performance on weekly practical task assessments, midterm practical exam and final practical exam in the preclinical restorative dentistry course.

Methods: Scores of final practical exam, midterm practical exam and weekly practical task assessments in the restorative dentistry preclinical course in the half year of the third year of the curriculum at Biruni University Faculty of Dentistry were compared. It was hypothesized that students that performed highly on weekly task assessments would perform highly on the midterm and final practical exams.

Results: The results showed that the weekly practical task assessment scores were correlated with the midterm practical exam and final practical exam scores and were a positive predictor. However, final practical exam scores were significantly lower than midterm practical exam and weekly practical task assessment scores.

Conclusions: The quality assessments of students' weekly tasks would be an effective predictor to assess student's preclinical performance. Thus, it would be recommended that integrating weekly task assessment into the preclinical restorative dentistry curriculum as an effective assessment tool.
\end{abstract}

Keywords: Preclinical examination, restorative dentistry, dental education

Received: March 2, 2018; Accepted: June 10, 2018; Published Online: June 23, 2018

$\mathrm{T}$ he one of the important components of preclinical dental education is a restorative dentistry course. Preclinical restorative dentistry courses enable students acquire and develop their manual dexterity and gain knowledge about the clinical aspects of to restoring carious and/or defective teeth [1]. Manual dexterity is a fundamental component in restorative dentistry, as fine motor skills are necessary to carry

out complex treatments in small dimensions, with limited space and visibility in the oral cavity $[2,3]$.

Dental students learn these fundamental skills through simulated exercise in preclinical courses using either artificial teeth mounted in phantom head or extracted natural teeth, before delivering actual patient care in the clinic. Therefore, dental students should acquire of these psychomotor skills during the preclinical course of restorative dentistry to be prepared to deliver real patient care in the clinics [4].

The final practical examination has generally a greatest influence for assessing students' preclinical success in restorative dentistry courses. Students must

Address for correspondence: Atilla Tekin, DDS, PhD., Biruni University, Faculty of Dentistry, Department of Restorative Dentistry, 10. Yll Cad., No:45, 34010 Istanbul, Turkey, E-mail: kerimayar@biruni.edu.tr, Phone: +90 2124448276, Fax: +90 2124164646 
take at least 50 out of 100 points in the final exam to pass the restorative practical lesson in the faculty of dentistry at Biruni University. The score on the final exam on the year-end grade is $60 \%$. The effect of the midterm exam was determined as $40 \%$ on the yearend grade. Weekly task assessments have not a direct numerical effect on the year-end score, but the completion of these tasks is a prerequisite for entering the final exam at the Biruni University. However, measuring student performance at a particular time, provide information about only single specific performance and not about psychomotor learning curve [3]. Therefore, validity of the final practical exam to assess whether student gained objective learning of restorative dentistry through the whole of preclinical course would be questionable.

The purpose of the present study was to determine if any correlations existed between dental students' final and midterm practical exam scores and their weekly task assessment scores in restorative dentistry preclinical course. It was hypothesized that students' performance in the preclinical restorative dentistry course would predict how successful they were in the clinic, using their weekly task assessment scores as a measure of performance instead of, or similar to final practical exam scores. It was claimed that students who did poorly work on weekly task assessments would receive low grades in the final exam in the present study. This correlation would recommend that weekly task assessment in a preclinical course is crucial in the improvement of manual dexterity and gaining dental knowledge needed for success in the clinic.

\section{METHODS}

Third-year students at dental school participate in a 16-week restorative dentistry preclinical course in the one semester during the Restorative Dentistry Practical Course at the Faculty of Dentistry of Biruni University in Istanbul, Turkey. A total of 84 dental students (50 females, 34 males) participated in the study. The participation of all students in the study was voluntary. Preclinical courses consisting of phantom head simulation sessions. The course curriculum through the semester was given in Table 1 . The weekly task assessments were conducted each week after the course sessions. All of weekly assessment scores (nine in total) were averaged to calculate the mean weekly assessment scores. All weekly assessments were equally weighted. Additional to completion of all of weekly assessments, students have to pass midterm and final practical exams (a scale of 0 to 100). A midterm practical exam was conducted at the 7 th week. The final practical exam was conducted in the last week of course. All assessments were performed by the same rater (M.K.A). Faculty and teaching assistants were available for additional feedback during preclinical course sessions. As usual, no feedback to students from the faculty stuff was given during mid and final practical exams.

Students were divided into three subgroups according to their weekly task assessment mean as following, lowest third, middle third and upper third to determine trends related to the midterm and final exams.

\section{Statistical Analysis}

Means and standard deviations were calculated for weekly task assessments, midterm exam and final exams. Comparison was made among averaged weekly task assessment scores, midterm exam and final exam scores, respectively. Paired t-tests were used for statistical analysis and the $p$-level was set at 0.05 . Also, mean weekly task assessments of each student was correlated with his or her midterm and final exam scores, respectively to assess the strength of the relationship. Statistical analysis was carried out using SPSS version 18.0 for Windows statistical software (SPSS Inc., Chicago, IL, USA).

\section{RESULTS}

The means and standard deviations of weekly task assessment scores, midterm exam scores and final exam scores of the students on the preclinical restorative dentistry course throughout the 16-week study are shown in Table 2 and Figure 1. For the mean weekly task assessment, the mean score was $84.2 \pm$ 8.7 with a range of 64.4 to 99.4 . For the midterm exam, the mean score was $76.7 \pm 13.7$ with a range of 40 to 95 . For the final exam, the mean score was 67.8 \pm 13.7 with a range of 35 to 100 . The coefficient of variation, a comparison measure of relative dispersion, 
Table 1. Preclinical restorative dentistry curriculum for third year student at Biruni University (20172018)

\begin{tabular}{|c|c|c|}
\hline Week \# & Preclinical course topic & Activity \\
\hline 1 & $\begin{array}{l}\text { Introduction to the use of phantom head and } \\
\text { working positions. Occlusal cavity } \\
\text { preparation for amalgam at the phantom. }\end{array}$ & Teeth 46 and $47 \mathrm{O}$ \\
\hline 2 & $\begin{array}{l}\text { Occlusal cavity and proximal cavity } \\
\text { preparations on plastic teeth at the phantom. }\end{array}$ & Teeth 26 and 27 O, Teeth 24 and 25 DO. \\
\hline 3 & $\begin{array}{l}\text { Complex cavity preparations at the } \\
\text { phantom. }\end{array}$ & $\begin{array}{c}\text { Tooth } 36 \mathrm{MOD} \text {, Teeth } 37 \mathrm{MO}, 34 \text { and } 35 \\
\text { DO. }\end{array}$ \\
\hline 4 & $\begin{array}{l}\text { Complex and cervical cavity preparations at } \\
\text { the phantom }\end{array}$ & $\begin{array}{c}\text { Teeth } 14 \text { MOD, } 15 \text { DO, and } 17 \text { DO, Tooth } \\
16 \text { occlusal and cervical. }\end{array}$ \\
\hline 5 & $\begin{array}{l}\text { Placement of glass ionomer base into the } \\
\text { prepared cavities at the third and fourth } \\
\text { lessons at the phantom. }\end{array}$ & \\
\hline 6 & $\begin{array}{l}\text { Cavity preparation and amalgam restoration } \\
\text { at the phantom. }\end{array}$ & Teeth $24 \mathrm{MO}, 25 \mathrm{DO}, 26 \mathrm{O}, 27 \mathrm{O}$ \\
\hline 7 & Midterm practical exam & $\begin{array}{l}\text { Amalgam restoration of tooth } 17 \mathrm{O} \text {, cavity } \\
\text { preparation for amalgam of tooth } 16 \mathrm{MO} \text {, } \\
\text { placement of glass ionomer base into tooth } \\
15 \mathrm{MO} \text {, placement of tofflemire matrice. }\end{array}$ \\
\hline 8 & $\begin{array}{l}\text { Re-preparation week. Students with } \\
\text { unacceptable performance in the previous } \\
\text { lessons redo their preparations in this week. }\end{array}$ & \\
\hline 9 & Composite restoration at the phantom. & Teeth $47 \mathrm{O}, 46 \mathrm{MO}, 45 \mathrm{MO}$ \\
\hline 10 & Composite restoration at the phantom. & Teeth 27 DO, 26 MOD, 24 DO \\
\hline 11 & $\begin{array}{l}\text { Carious removal and composite restoration } \\
\text { with extracted human teeth }\end{array}$ & \\
\hline 12 & $\begin{array}{l}\text { Proximal cavity preparation for anterior } \\
\text { teeth at the phantom. }\end{array}$ & Teeth $13,12,11,21,22,23$ \\
\hline 13 & Composite restoration at the phantom. & Teeth $13,12,11,21,22,23$ \\
\hline 14 & $\begin{array}{l}\text { Anterior tooth fracture preparation and } \\
\text { restoration with resin composite }\end{array}$ & Teeth 11,21 \\
\hline 15 & $\begin{array}{l}\text { Tooth preparation for composite laminate } \\
\text { veneer. }\end{array}$ & Teeth $11,12,21,22$ \\
\hline 16 & Final Exam & $\begin{array}{c}\text { Tooth } 46 \text { DO amalgam cavity preparation } \\
\text { with base placement, tooth } 16 \mathrm{DO} \\
\text { composite restoration, tooth } 17 \mathrm{DO} \\
\text { amalgam restoration, tooth } 45 \mathrm{MOD} \text { cavity } \\
\text { preparation for amalgam, placement of } \\
\text { ivory matrice. }\end{array}$ \\
\hline
\end{tabular}

$\mathrm{MO}=$ Mesial + Occlusal, $\mathrm{DO}=$ Distal + Occlusal, $\mathrm{MOD}=$ Mesial + Distal + Occlusal

showed that the Mean Weekly Task Assessment varied in a narrow range $(10.3 \%)$ while the midterm exam $(17.9 \%)$ and final exam (30\%) data were much more volatile.
Gradually increasing trends to the midterm exam and the final exam may be seen. The standard deviations were of similar value throughout the study period. Preparation of the complex and compound 
Table 2. Descriptive statistical measures

\begin{tabular}{lccc}
\hline Variable & Mean \pm Standard Deviation & Coefficient of variation & Min - Max \\
\hline Mean Weekly Task & $84.2 \pm 8.7^{\mathrm{a}}$ & $10.3 \%$ & $64.4-99.4$ \\
Assessment & & & \\
Midterm Exam & $76.7 \pm 13.7^{\mathrm{b}}$ & $17.9 \%$ & $40-95$ \\
Final Exam & $67.8 \pm 13.7^{\mathrm{c}}$ & $30 \%$ & $30-100$ \\
\hline
\end{tabular}

Different superscripts indicate significant differences in the same column $(p<0.05)$

cavity preparations showed gradual improvement from the second week to seventh week with reaching a plateau. The mean weekly task assessment is significantly higher than those of midterm exam ( $p=$ $0.01)$ and final exam $(p=0.01)$ respectively. Mean of the final exam is significantly lower the mean of midterm exam $(p=0.01)$.

Trends related to the midterm and final exams, among three subgroups including lowest third, middle third and upper third were shown in Figure 2. Students' performances were lowered at the midterm exam and final exam weeks, regardless their weekly task assessment means.

Correlation coefficients between the mean weekly task assessment and midterm exam score $(\mathrm{r}=0.623)$, between the mean weekly task assessment and final exam score $(\mathrm{r}=0.543)$, and between midterm exam score and final exam score $(\mathrm{r}=0.413)$, confirming relationship between practical measurement tools.

\section{DISCUSSION}

The results of the present study indicate correlations among assessment scores of student's weekly tasks and both of midterm and final practical exam scores, respectively. This confirms that student performs well at weekly task assessments likely will show better performance at the midterm and final practical exams. Therefore, we could accept that students' weekly performance scores would be a good predictor for final and midterm practical exam scores of the students, thus for clinical success. Additionally, these findings are consistent with Velayo et al. [5], who demonstrated a positive relationship between the preclinical and clinical performance of students.

The eventual aim of the preclinical restorative dentistry course is to get ready students to provide the best patient care in the clinic. It is estimated that students then continue to build on that base through

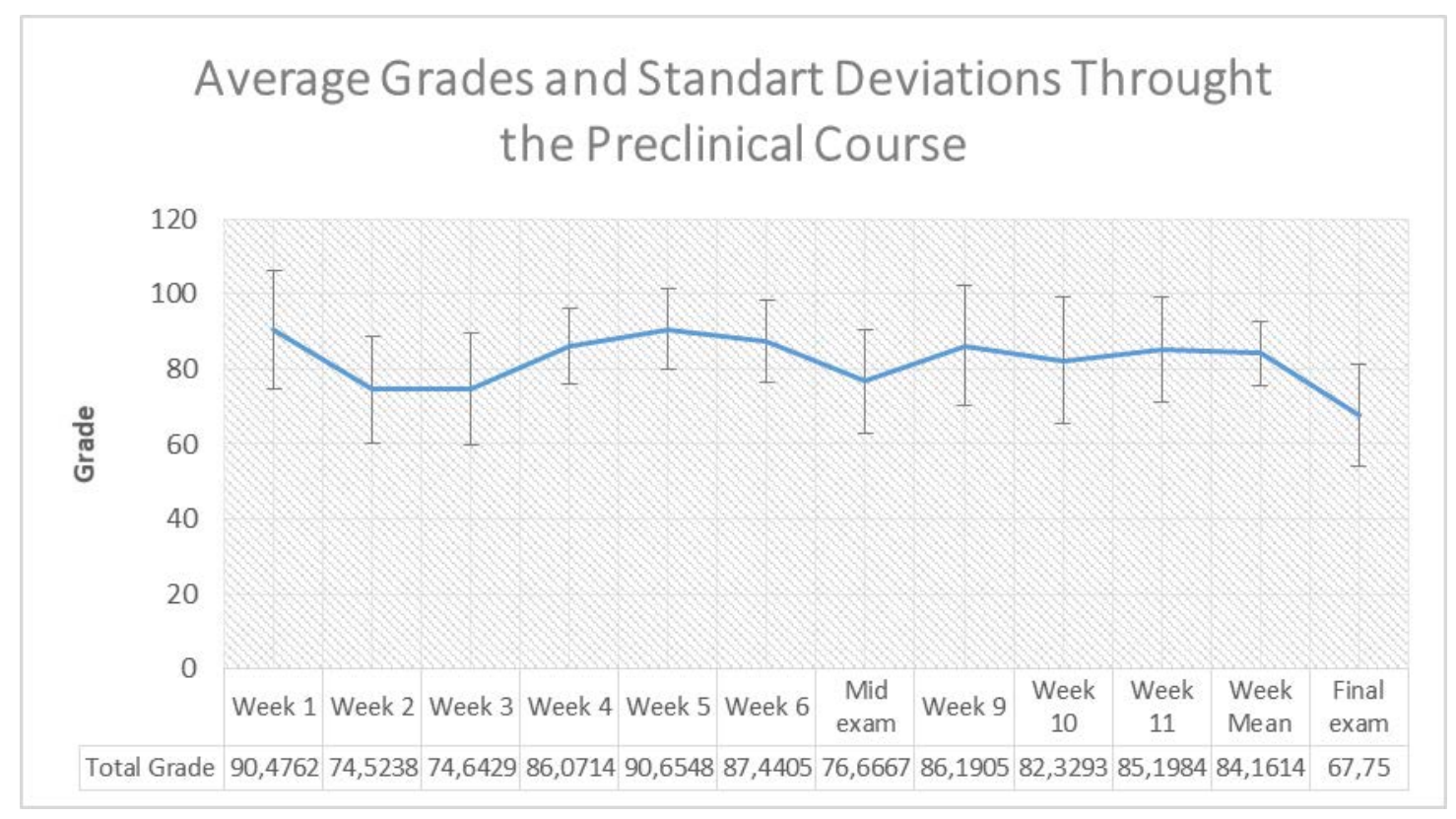

Figure 1. Average grades and standard deviation through the preclinical restorative dentistry course. 


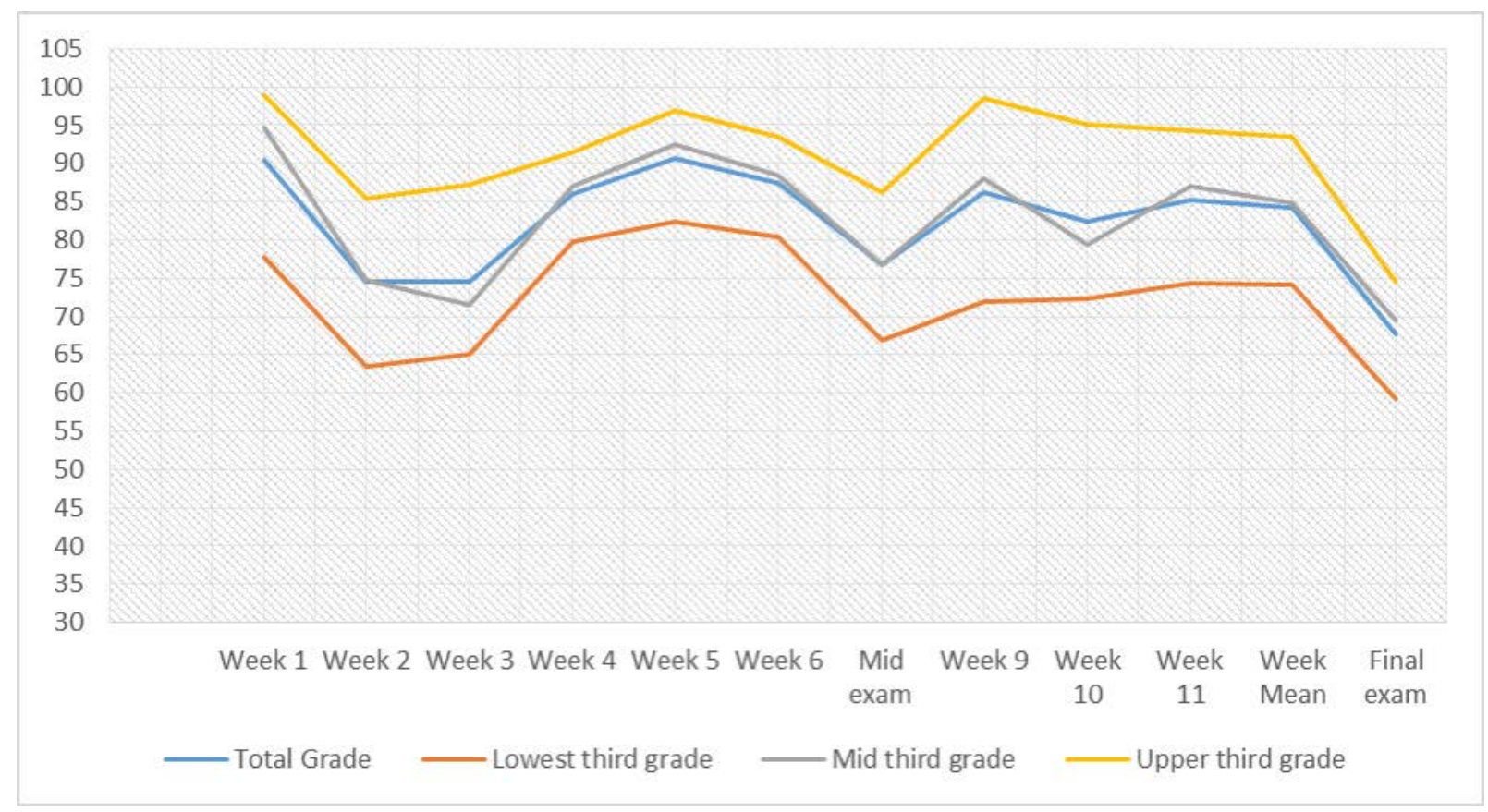

Figure 2. Grades of three subgroups of students $(n=27)$ according to weekly task assessment mean.

their clinical course and graduate to enter practice. This study indicates that the learning that takes place in the preclinical restorative dentistry course may persist in the clinic. The extra practice could be extremely effective since psychomotor skills improve with repetition $[5,6]$. In addition, it would be logical that quality examination of each task performed by students during the weekly practical sessions by the faculty would encourage the students for increasing their work quality due to the fear of re-doing the task. This method would eventually further help to improve psychomotor skills along with the knowledge required to delivered patient care in the clinic.

One of the highlighting findings is that student's weekly task assessment scores are significantly higher than those of midterm and final practical exam scores, respectively. Also, this finding did not depend on student's weekly task assessment means. Students from lowest third of weekly assessment mean or students from upper third of weekly assessment mean generally showed better performance at weekly assessments than midterm and final exams. One possible explanation would be an immediate feedback, which occurs between student and instructor during preclinical session. The feedback enables student to recognize their errors and learn the way to correct them. However, similar interaction is not allowed during examination sessions, as usual. Therefore, students yield making more errors during midterm and final exams, lowering their scores.

Another reason why final exam scores are lower than midterm exam scores and the weekly task assessment score would be the stress of final exam that students live in the final exam. It can be suggested that the ultimate impact of final exam scores on end-year score of the student likely overwhelmingly stresses students, making probably them prone to make more errors during the final exam performance. The previous studies proposed that one of the major factors, which stress students during their education, is fear of failing course or year $[7,8]$. The findings of the present study support this suggestion.

\section{CONCLUSION}

As a conclusion, weekly assessments of quality of student's tasks would be an effective predictor to assess student's preclinical performance as well as a final practical exam. However, it would fit better for student perspective as students live likely lower stress than that in the final exam. Therefore, it would be 
recommended that integrating weekly task assessment into the preclinical restorative dentistry curriculum as an effective assessment tool.

\section{Conflict of interest}

The author disclosed no conflict of interest during the preparation or publication of this manuscript.

\section{Financing}

The author disclosed that he did not receive any grant during conduction or writing of this study.

\section{REFERENCES}

[1] Ayar MK. Dental students' perceptions on preclinical restorative dentistry course: Biruni University case. Eur Res J 2018;4:199-204.

[2] Luck O, Reitemeier B, Scheuch K. Testing of fine motor skills in dental students. Eur J Dent Educ 2000;4:10-4.

[3] Ben-Gal G, Katorza L, Weiss EI, Ziv A. Testing motor learning curves among dental students. J Dent Educ 2017;81:1171-8.

[4] Suksudaj N, Townsend G, Kaidonis J, Lekkas D, Winning T. Acquiring psychomotor skills in operative dentistry: do innate ability and motivation matter? Eur J Dent Educ 2012;16:e187-94.

[5] Velayo BC, Stark PC, Eisen SE, Kugel G. Using dental students' preclinical performance as an indicator of clinical success. J Dent Educ 2014; 78:823-8.

[6] Chaiken SR, Kyllonen PC, Tirre WC. Organization and components of psychomotor ability. Cogn Psychol 2000;40:198-226.

[7] Polychronopoulou A, Divaris K. Perceived sources of stress among Greek dental students. J Dent Educ 2005;69:687-92.

[8] Abu-Ghazaleh SB, Sonbol HN, Rajab LD. A longitudinal study of psychological stress among undergraduate dental students at the University of Jordan. BMC Med Educ 2016;16:90. 